\title{
Heat-health action plans in Europe: Challenges ahead and how to tackle them
}

Martinez, Gerardo S.; Linares, Cristina; Ayuso, Ana; Kendrovski, Vladimir; Boeckmann, Melanie; Diaz, Julio

\section{Published in:}

Environmental Research

Link to article, DOI:

10.1016/j.envres.2019.108548

Publication date:

2019

Document Version

Peer reviewed version

Link back to DTU Orbit

Citation (APA):

Martinez, G. S., Linares, C., Ayuso, A., Kendrovski, V., Boeckmann, M., \& Diaz, J. (2019). Heat-health action plans in Europe: Challenges ahead and how to tackle them. Environmental Research, 176, [108548].

https://doi.org/10.1016/j.envres.2019.108548

\section{General rights}

Copyright and moral rights for the publications made accessible in the public portal are retained by the authors and/or other copyright owners and it is a condition of accessing publications that users recognise and abide by the legal requirements associated with these rights.

- Users may download and print one copy of any publication from the public portal for the purpose of private study or research.

- You may not further distribute the material or use it for any profit-making activity or commercial gain

- You may freely distribute the URL identifying the publication in the public portal

If you believe that this document breaches copyright please contact us providing details, and we will remove access to the work immediately and investigate your claim 


\title{
Heat-Health Action Plans in Europe: Challenges ahead and how to tackle them
}

\author{
Gerardo S. Martinez, The UNEP DTU Partnership, Copenhagen, Denmark \\ Cristina Linares, Carlos III National Institute of Health, Madrid, Spain \\ Ana Ayuso, Carlos III National Institute of Health, Madrid, Spain \\ Vladimir Kendrovski, World Health Organization Regional Office for Europe, Bonn, Germany \\ Melanie Boeckmann, School of Public Health, Bielefeld University, Bielefeld, Germany \\ Julio Diaz, Carlos III National Institute of Health, Madrid, Spain
}

\section{Abstract}

High temperatures have periodically affected large areas in Europe and urban settings. In particular, the deadly 2003 summer heat waves precipitated a multitude of national and subnational health prevention and research efforts. Building on these and other international experiences the WHO Regional Office for Europe developed and published in 2008 a comprehensive framework for prevention, the heat-health action plans (HHAPs). This provided a blueprint used by several national and subnational authorities to design their prevention efforts. A decade after the publication of the WHO guidance, a wealth of new evidence and acquired implementation experience has emerged around HHAP effectiveness; heat exposure; acclimatization and adaptation; heat-health governance and stakeholder involvement; and the role of urban design and greening interventions in prevention. This evidence and experience can guide the strategies to tackle current and upcoming challenges in protecting health from heat under a warming climate.

Key words: Heat Wave; Heat-Health Action Plan; Climate Change; Adaptation

\section{Protecting health from heat: the WHO 2008 Heat Health Action Plan Guidance}

Heat waves have periodically constituted an environmental health risk in large areas of Europe, but the 2003 summer heat waves were a defining event, both in terms of public attention and increased research into heat and health. Robine et al. (2008) estimated these heat waves led to 70,000 excess deaths. These events led to the development of the first large scale efforts of public health prevention of heat waves in the region. Based on these initial experiences and the best evidence at the time, the WHO Regional Office for Europe (2008) identified core elements that such prevention activities should encompass and incorporate into comprehensive heat-health action plans (HHAPs).

These core elements, elaborated upon in the WHO guidance, include:

- Agreement on a lead body to coordinate a multipurpose collaborative mechanism between bodies and institutions and to direct the response if an emergency occurs;

- Accurate and timely alert systems: heat-health warning systems trigger warnings, determine the threshold for action and communicate the risks;

- A heat-related health information plan about what is communicated, to whom and when;

- A reduction in indoor heat exposure: medium- and short-term strategies, including but not limited to advice on how to keep indoor temperatures low during heat episodes;

- Particular care for vulnerable population groups, including identification, localization and outreach;

- Preparedness of the health and social care system, including staff training and planning, appropriate health care and the physical environment;

- Long-term urban planning, addressing building design and energy and transport policies that will ultimately reduce heat exposure; and

- Real-time surveillance of heat-related health outcomes and evaluation of both process and outcomes; 
Soon thereafter, in the summer of 2010, many eastern European cities recorded extremely high temperatures, particularly in the Russian Federation, where the deaths attributable to high temperatures and smoke of wildfires were estimated at around 55,000 (Barriopedro et al., 2011). As a response, the WHO Regional Office for Europe updated and expanded the set of information sheets annexed to the HHAP guidance, providing targeted heat-health advice for the general public, medical professionals and health services (WHO, 2011). The WHO HHAP framework and accompanying materials have been subsequently adopted as a blueprint for prevention by various WHO European Member States, both within and outside the European Union, as well as subnational and local authorities therein.

In the last decade, several member states in the WHO European Region have implemented HHAPs of varying scopes and complexity. As of 2018, there were operational HHAPs in 35 out of 53 member states of the WHO European Region (GHHIN, 2018), though many of those HHAPs are subnational, mostly administered by regions or provinces. Various major cities have their own plans, though by and large, the active participation of local governments in HHAPs in Europe is limited, and typically restricted to large cities with high resource availability and capacity. Parallel to the implementation of prevention there has been a great increase in research and publications on HHAPs, both globally (in particular in OECD countries) and in Europe (Campbell et al., 2018). The integration of state-of-the-art knowledge is fundamental to ensure that HHAPs can deliver on their potential benefits. A significant collection effort with a global scope resulted in a detailed compilation of evidence specifically relevant to heat-health warning systems globally, commissioned by WHO to leading experts in the field (WHO/WMO, 2015). Similarly, the operational relevance of WHO EURO's HHAP guidance requires the periodical integration therein of the best available evidence, adequately reviewed and packaged into formats that are actionable by practitioners and decision makers. Mindful of this need, the WHO Regional Office for Europe laid out in 2018 a roadmap of activities involving relevant stakeholders at different stages and capacities, in order to collect and analyze updated evidence. As part of this process, WHO commissioned systematic literature reviews and held expert group meetings, from which relevant trends and gaps in knowledge were identified, and future directions suggested for both additional research and operational considerations for HHAP deployment and evaluation. All the reviews and expert meetings were focused mainly on evidence and considerations for the WHO European Region, although selected evidence from elsewhere is considered where relevant. That is also the main focus of this article, where we use "Europe" and "the WHO European Region" interchangeably.

\section{Key strategic insights from the last decade of evidence on HHAPs}

A large amount of research has emerged since the first edition of the WHO HHAP guidance, concerning important factors for the prevention of health effects from heat. Specifically, an important corpus of additional evidence on the effectiveness of current heat-health prevention strategies in averting, reducing or minimizing heat-related mortality and morbidity has been published. There is also additional evidence on how climate change, population ageing and urbanization affect heat-related mortality and morbidity; something crucial, since most current HHAPs do not address the question of whether and how their core elements should evolve in a changing climate, shifting demographics and increasingly urban populations.

\section{Global trends, acclimatization and adaptation}

In terms of observed climate trends, the frequency, intensity (relative and absolute) and duration of heat waves has significantly increased in Europe since 1950 (Donat et al., 2013). The number of "hot days" (i.e. those with maximum temperature above the $90^{\text {th }}$ percentile threshold over a reference period) has increased ten days per decade since 1960 in most of Southeast Europe and Scandinavia, and six out of the top ten heat waves between 1950 and 2015 in the region occurred after the year 2000 (Russo et al., 2015). Temperatures will continue to increase throughout the twenty-first century, more quickly in Europe on average than the rest of the planet according to EURO-Cordex (Jacob et al., 2014). Greater temperature increases are expected in Northwest Europe and Scandinavia in winter and in Southeast Europe in the summer (European Environment Agency, 2017). Increasing heat exposure is also expected to progressively 
reduce labor productivity, particularly in southern Europe (Levi et al., 2018). Under a no longer unrealistic RCP8.5, the probability that any summer during the period 2061-2081 will be globally warmer than the hottest on record is $80 \%$, though adequate mitigation could reduce risk in Europe by more than $50 \%$ (Lehner et al., 2018). It is thus clear that exposure to extreme heat has been worsening in the last decades, and will continue to worsen in the region.

Whether and how that has translated and will translate into health impacts is less obvious. Over the last few decades, several studies indicate decreasing trends of heat-related health impacts in several regions of the world. Various rates of decrease of heat-related all-cause mortality have been observed in Japan (Chung et al., 2018), Australia (Coates et al., 2014) and the US (Barreca et al., 2016). In Europe, decreases have been observed in Spain (Díaz et al., 2018), Ireland (Pascal et al., 2013), the Czech Republic (Kyselý and Kríz, 2008), and in the UK (Green et al., 2016; Arbuthnott and Hajat, 2017). On the other hand, in France excess mortality during the 2015 heat waves was higher than for the 2006 ones (Ung et al., 2019). Overall, however, while the population exposed to dangerous heat waves doubled between 1971-2003 and 2004-2013 in France, mortality response to heat remained unchanged (Pascal et al., 2019), which suggests both a protective effect of the national HHAP and that large heat-related health impacts remain possible. A multicity study of nine European cities showed a reduction in mortality due to heat in Mediterranean cities but not in cities in Northern Europe, a difference the authors attribute to the implementation of prevention plans, a greater level of adaptation of the local population and greater media-related awareness of the population about exposure to heat (de' Donato et al., 2015; Scortichini et al., 2018). Within the observed decreases in health impacts there is variability too; in some cases decreases were observed for both cardiovascular and respiratory mortality (Bobb et al., 2014; Ng et al., 2016), in others only for cardiovascular mortality (Miron et al., 2015; Muthers et al., 2010). Regarding morbidity, trends are even less consistent, with some studies finding decreases in heat-related cardiovascular morbidity (Fechter-Leggett et al., 2016) and others finding increases in hospitalizations and ambulance calls for heat-related illnesses (Nitschke et al., 2011). Most studies in Europe and internationally have not found gender differences in the decrease of heat-related mortality (Sheridan and Allen, 2018), and there is little evidence of differences in reductions across age groups (Coates et al., 2014; de’ Donato et al., 2015).

Regarding future scenarios, several projections of the possible impact of heat on future mortality consider a fixed, unchanging threshold temperature based on retrospective observations. Under this hypothesis (i.e. a fixed threshold temperature for heat-related mortality), and as a consequence of the projected increase in temperatures associated with climate change (IPCC, 2013), large increases in mortality attributable to heat have been projected (Ciscar et al., 2014; Forzieri et al., 2017; Hajat et al., 2014; Petkova et al., 2014; Roldan et al., 2014; Wu et al., 2014). The assumption of an unchanging threshold temperature, however, merits scrutiny. For instance, population ageing (widely observed throughout the WHO European region) would influence (i.e. reducing) such threshold, by virtue of increasing the pool of vulnerable individuals (people over age 65) (Carmona et al., 2016; Montero et al., 2012). While modelling is inherently uncertain and relies to an important extent on the scenarios and assumptions underlying its projections, a large-scale global study in 2017 modelled an increase in both heat- and cold-related excess mortality using high-emissions scenarios (Gasparrini et al., 2017). Local contexts and local effects of global changes may differ from global scenarios; however, and estimates for temperate European regions show larger reductions in cold-related excess mortality whereas estimates for warmer Southern European regions indicate an increase in excess heat-related deaths (Gasparrini et al., 2017). These findings suggest that even time series on HHAP effects from one location may not be automatically applicable to a different one, requiring careful contextual adaptations.

Moreover, assuming a complete absence of adaptive processes is unrealistic, although it can serve an important role as a counterfactual scenario for policy advocacy. In reality, variable levels of autonomous and planned adaptation are to be expected even in the absence of large and concerted efforts by national governments. A certain degree of "autonomous" adaptation may be expected from individuals and families, for example through an increase in the number of air conditioning units (Díaz et al., 2018). From the "planned adaptation" side, these would include a further development of a "culture of heat" (Bobb et al., 2014); the implementation of prevention plans (Schifano et al., 2012; van Loenhout and Guha-Sapir, 2016); and improvements in health services (Ha and Kim, 2013), among other factors. In addition to active adaptation, there is a certain degree of physiological acclimatization to heat, though this is assumed to be 
quite limited until reaching "Peak Heat Stress" (Sherwood and Huber, 2010). Generally, a "no adaptation" assumption is better suited as a counterfactual for agenda setting and policy advocacy than a realistic baseline scenario. This does not diminish the urgency of undertaking large adaptive efforts, nor does it discount the possibility of heat-related impacts severe enough to overwhelm institutional, autonomous and physiological adaptations.

The observed and projected trends have significant implications for the effectiveness of prevention, currently and in the context of building adaptive capacity for forthcoming climate change impacts. To identify challenges and opportunities, the "shared socioeconomic pathways" (possible pathways of future development) are increasingly used to build scenarios for strategies to transition into more sustainable and resilient futures (O’Neill et al., 2017).

\section{Effectiveness of HHAPs: the importance of "last mile" factors}

Assuming as generally true (i.e. extrapolating the observed results to the whole region) the overall decreasing trend of heat-related mortality (and presumably morbidity) in Europe, we still do not have a full understanding of how much heat-health prevention in general, and specifically HHAPs, may have contributed to it. Reviews (Toloo et al., 2013) (Boeckmann and Rohn, 2014) show inconclusive results in terms of how effective heat warning systems are in reducing mortality and morbidity, suggesting that HHAPs may by themselves have a limited effect of impact in reducing heat-related deaths and illness. Whether specifically a HHAP is responsible for reduced mortality during extreme heat events over time is difficult to assess even with before and after study designs, due to the variety of potential confounding factors that must be included in models, and frequently a lack of information of user engagement with the warnings: were warnings merely issued, or did they lead to behaviour change? While the overall beneficial effect of HHAPs is not under discussion, the factors leading to their effectiveness or lack thereof are not well understood at the moment (Ragettli and Röösli, 2019), warranting a closer look at various factors of relevance.

The first important factor is the diversity of interventions and arrangements that are categorized as HHAPs or similar prevention plans. As of late 2013, 18 European countries had national level HHAPs, (Bittner et al., 2014) and several others have followed thereafter. In several countries, additional subnational (regional and provincial) plans are in place, and a few major cities have their own plans - an upcoming survey will provide a more updated overview. This complex landscape is evolving quickly, with almost complete subnational HHAP coverage in some countries and quick progress in others, as reported by HHAP administrators to the WHO Regional Office for Europe (REF meeting report). Therefore, some regions and urban settings could be currently benefitting from concurrent layers of prevention whereas others may have in place no HHAP-related activity or only limited national-level activities (consisting at their most basic of heat wave warnings coupled with non-targeted information campaigns). Moreover, in the territories and areas nominally covered by a HHAP, the number of "core elements" addressed in the plan, as well as the resources for implementation may also vary. Not surprisingly, Bittner et al. (2014) found greater implementation of the more basic core HHAP elements (lead body, alert systems, health information plan) than of those requiring more resources (e.g. surveillance, monitoring and evaluation) or spanning beyond the competencies of health systems (long-term inter sectoral action and measures, including urban management).

While the diversity in HHAP implementation precludes aggregation, heat-related health impacts can be compared before and after the intervention in settings where either HHAPs or other types of prevention have been implemented. For example, in France Fouillet et al., (2008) observed a 68\% reduction of "expected" deaths during the heat wave of 2006, benefitting especially those over age 75 years, an effect that could be attributed to a variety of factors, including the implementation of the prevention plan and alert system after the heat wave of 2003. As mentioned, however, recent evaluations suggest that heatrelated risk in France is only partially being controlled through prevention (Pascal et al., 2019). A study of 23 Italian municipalities observed a progressive reduction in heat related over 12 years since the introduction of heat preventive measures, both overall and when heat warnings are issued and preventive measures are in place (de'Donato et al., 2018). In the city of Florence heat-related mortality risk for those 
aged 75 or older dropped from $23 \%$ in 1999-2002 (without a prevention plan) to $21 \%$ for the period 2004 05 (with a prevention plan) and to 12\% for the period 2006-07 (Baccini et al., 2011). Studies suggest that prevention plans were especially successful among older people due to the campaigns that targeted them specifically (de'Donato et al., 2018; Pascal et al., 2019). The German national HHAP, as well as related subnational ones, are credited with reducing heat-related health outcomes (Matzarakis, 2017) and HHAP in Swiss cantons have also shown a protective effect (Ragettli and Röösli, 2019), while acknowledging that extreme heat events pose additional challenges to heat protection. However, there are discordant results. For example, in Athens, one of the hottest cities in Europe and a place where the impact of high temperatures is greatest, there has also been a decrease in mortality due to heat among elderly people, despite not having a prevention plan (de' Donato et al., 2015). In the city of Madrid, the implementation of a HHAP did not seem to decrease heat-related mortality in the 2005 heat wave, less intense than that of 2003 but deadlier on the basis of mortality increase per $1^{\circ} \mathrm{C}$ hike in temperature (Culqui et al., 2014). Moreover, other studies show that the decrease in heat-related mortality in Spain cannot be consistently attributed to prevention plans and that it varies spatially (Linares et al., 2015).

Other factors that could be hindering HHAP effectiveness include difficulties in reaching or engaging vulnerable groups, low involvement of local governments, and low risk perceptions of both vulnerable groups and health practitioners (Wolf et al., 2010a). Together, these factors amount to a "last mile" failure of otherwise well designed, activated and operated HHAPs.

The low risk perception of vulnerable groups observed in Europe and elsewhere (Abrahamson et al., 2009; Akompab et al., 2013; Gil Cuesta et al., 2017; Howe et al., 2019; van Loenhout and Guha-Sapir, 2016) is of particular concern, suggesting that while plans and alert systems may raise awareness, they may not be able to prompt self-protective actions. This phenomenon is not particular to heat exposure: the theories of health promotion and behavior suggest that those most likely to adopt these measures are also those who feel most threatened, and awareness does not necessarily equate with perceived threat. The low perception of risk among the most vulnerable groups and the cost of engaging in protective measures against heat such as the cost of air conditioning - are some of the barriers that prevent the population from taking action (van Loenhout, Rodriguez-Llanes, \& Guha-Sapir, 2016). Factors mediating heat-health risk perception and behavioral responses are being analyzed more systematically by researchers, and found to be highly context specific. For instance, a survey revealed better practices against heat by those who had obtained information in Portugal, a result also observed in France (Bassil and Cole, 2010). Heat risk perception and adaptive capacity does not relate to social capital in an intuitive manner; that is, strong networks do not necessarily contribute to a more accurate risk perception and better self-protection (Abrahamson et al., 2009; Wolf, Adger, Lorenzoni, Abrahamson, \& Raine, 2010). Even when they are related (i.e. a stronger social network is associated with a more accurate risk perception) that may not result in better adaptive behaviors during a heat wave, which may in turn be related to other factors such as more education or higher income (Akompab et al., 2013). Recent research reinforces the importance of social processes in enhancing or limiting climate resilience measures (Howarth et al., 2019). Beyond social capital, broader factors also influence the uptake of protective behaviors, some of which can be targeted by education and outreach. For instance, social norms campaigns to increase acceptability of free use of cool spaces such as banks or supermarkets without purchasing anything were found to be needed in Japan (Sanchez Martinez et al. 2011; Boeckmann 2016). Changing knowledge, attitudes, practices and beliefs (KAPB) regarding the effectiveness of an intervention is another approach that can be taken. Up to now surveys assessing KAPB in general populations towards health have been conducted in several countries, for example in China (Li et al., 2016; Xu et al., 2018; Ye et al., 2018), Japan (Takahashi et al., 2015), Portugal and Spain (Gil Cuesta et al., 2017), as well as in the United States (Madrigano et al., 2018). Findings from such studies could be translated into target-group specific health education. Feelings of self-efficacy among those addressed by heat health behavior change advice may also need to be strengthened, and heat education campaigns could profit from strong theoretical frameworks grounded in behavior change theory (Lorencatto et al., 2013; Michie et al., $2013,2011)$, as is often the case for other behavior change interventions such as smoking cessation or increasing physical activity (Jepson et al., 2010). Finally, assessing whether heat health communication is conceived as risk communication during extreme weather events, or conducted as part of more general climate change communication (MacIntyre et al., 2019) could highlight opportunities for further linking outreach to perceived risks among communities. Ultimately, the effectiveness of behavioral guidance should be grounded on an accurate understanding of motivations behind risky behaviors (Ban et al., 2019) and 
possibly risk denial as a coping strategy (Bittner \& Stößel, 2012). Ideally, such understanding of specific "risk signatures" should come from the HHAP monitoring and evaluation (WHO/WMO, 2015), ensuring that the perspectives of vulnerable groups are adequately integrated into the system (Mayrhuber et al., 2018).

There are also indications that the risk perception of health providers themselves on heat seems may be significantly lower than it should, given the objective risks faced by their patients (Abrahamson \& Raine, 2009; Herrmann \& Sauerborn, 2018). Though the evidence is limited, an unrealistically low risk perception of heat by practitioners could severely hinder the implementation and effectiveness of HHAPs, highlighting the need for engagement of medical associations and other relevant bodies in disseminating the relevant information and offering capacity building opportunities.

\section{Governance and stakeholder involvement}

Most HHAPs and health-relevant adaptation strategies in Europe are designed for the national level (Boeckmann and Zeeb, 2014). Heat-health action plans in the WHO European region are typically managed at the national level and implemented by national and regional agencies, following distributions of competencies over health systems. Studies have analysed the organization of HHAPs (Austin et al., 2016; Bittner et al., 2014; Lowe et al., 2011; Matthies and Menne, 2009), showing some basic patterns: 1) Whether the HHAP is managed at national or local/regional level largely mirrors the overall decentralization of competencies in the country; 2) The development of an adaptation plan or HHAP is typically led by either the Ministry of Health or Ministry for the Environment, whereas sub nationally, response coordination is most often led by departments of health; and 3) Warnings are based on information provided by weather services while actions can be triggered by individual agencies or coordinated action.. National and/or subnational health services are usually informed about heat events and often disseminate this information and take action.

Wherever HHAPs have been evaluated, the focus has been on whether the system has contributed to fewer deaths - the counterfactual being absence of the HHAP and not a different organization of it. The published literature does not provide sufficient information at this point to identify the most effective HHAP governance design; rather. More operational research into the governance of HHAP would be useful to illustrate the advantages and disadvantages of different organizational arrangements and governance modes of HHAPs. The published literature suggests, however, that governance arrangements favoring local involvement in implementation, including better stakeholder engagement, contribute to reaching out more effectively to vulnerable groups.

Governance of HHAP can also be examined by comparing national or regional approaches and developing "current practice" examples. However, management practices at one location or setting may not be applicable elsewhere due to the range of different health systems and their organization across Europe. In addition, without longer term evaluation of a number of governance approaches, whether the examples in place are actually the best practice or just the chosen practice needs to be analysed first. Regardless of the limitations of international comparison, local authorities are well positioned to make public health interventions more effective through a number of factors (UKDH, 2011): a) Direct accountability of results to the local communities; b) Ability to tailor services to local needs; and c) Ability to act on social determinants of health and health inequalities. These strengths are particularly useful for prevention strategies requiring stakeholder engagement and effective outreach to target groups. The involvement of local governments in HHAPs, as well as more generally in health adaptation, is hindered by a lack of awareness and political commitment about the need to address climate change drivers and impacts, inadequate governance structures, a scarcity of data and a lack of specialized knowledge (EU, 2013).

The involvement of local governments can be facilitated through the provision of information and support to the local employees involved and the integration of HHAP efforts into existing structures. Through such involvement, HHAPs could tap into the large potential of local volunteering structures, community capacity and in-depth knowledge of local needs. Inviting these stakeholders to the table early on in the design of HHAP and before implementation could highlight gaps or barriers to effective communication or outreach strategies. It is important to note that some of these stakeholders have been successfully engaged in some 
settings (e.g. Japan, see Martinez, Imai and Masumo, 2011; Boeckmann and Rohn, 2014) proving the value of these efforts. Strategies for increasing participation from communities can be borrowed from an extensive body of knowledge on increasingly common participatory research approaches and "urban lab" real world experiments in urban climate change mitigation and adaptation activities (Bulkeley and Castán Broto, 2013; Castán Broto and Bulkeley, 2013). In addition, cities or municipalities close to a national border within Europe may consider integrating warning systems and communication strategies in a cross-border approach, as populations are likely moving between countries for work or leisure.

\section{Urban management interventions}

The urban structure can further aggravate heat risks, especially during the night due to the absorption and slow liberation of heat from buildings and other heat-retaining surfaces, the residual heat from energy use and the lack of humidity on the land's surface (Bohnenstengel et al., 2011; Heaviside et al., 2017; Wilby et al., 2011). These factors increase temperatures in urban areas predominantly during nighttime, a phenomenon known as the Urban Heat Island (UHI) effect which can result in effective nighttime air temperature differentials of up to $3-12^{\circ} \mathrm{C}$ in large cities compared with surrounding rural areas (Memon et al., 2008). Urban areas in Europe and elsewhere are more vulnerable to the effects of heat (Burkart et al., 2011; Tan et al., 2010). What the empirical effect of related interventions is or could be is less clear. While landscape and infrastructure modifications such as green and blue spaces, green roofs and others are commonly expected to reduce heat-related health risks, the actual effect of those interventions is difficult to prove (Hondula et al., 2018). Key questions to explore further include: How much can realistic urban management interventions reduce effective temperatures in the (largely indoors) places where dangerous heat exposures also occur? Are health benefits considered and/or evaluated in these types of interventions? Do certain interventions (e.g. white roofs) provide more protection per unit invested than green spaces? Concerning green spaces, by far the best studied type of intervention, questions include: What arrangements and types of urban green space (e.g., trees vs grass) save more lives? What is the maximum protective effect that could be expected from large deployments of green spaces? And what are the potential benefits and costs of alternative interventions, including access to air conditioning and actions targeting the workplace?.

In addition to the additional research into urban greening and design solutions, there should be a much deeper discussion about the role of building insulation, building envelope, building design, ventilation possibilities and shading in general, given the key role these factors play in thermal comfort and heat stress (Hatvani-Kovacs et al., 2018; Loughnan et al., 2015). Some factors, like the degree of home maintenance, housing-material quality, and thermal insulation have been shown to play a crucial role in modulating the effects of heat waves (López-Bueno et al., 2019). Adequate retrofitting of existing buildings could greatly increase heat wave resilience, and a wide range of applied research is being conducted on design, materials and coating colors, among others. However, a range of regulatory and other types of barriers (for instance, lack of specialized technical knowledge and/or standard operating procedures for inspection) may prevent effective action on preventing building overheating as a public health risk, as noted in the UK (House of Commons, 2018a).

Another built environment solution that warrants further scrutiny in terms of heat, health and climate change is air conditioning, a crucial technology to protect vulnerable groups from high temperatures as well as refrigerating essential medicines. Although there are no estimates of how much air conditioning has decreased heat-related mortality, air conditioning air conditioning can be reasonably assumed to have had an influence in the decreasing trends of heat-related mortality in recent years in Europe. One of the reforms in the aftermath of the 2003 heat waves was making air conditioning mandatory in several types of institutions including nursing homes throughout various EU countries, notably France (Klenk et al., 2010). Air conditioning is, however, also Greenhouse Gas-intensive and should therefore not be advocated for as a main pillar of HHAPs beyond ensuring protection for vulnerable groups. Moreover, from the standpoint of health adaptation governments and institutions ought to be cautious about promoting a measure that clearly worsens Climate Change without some type of offsetting or in-built sustainability provisions. However, individuals, families and companies also engage in adaptation, and the trends concerning air conditioning are astounding. At current growth rates, the IEA reckons 1 billion air conditioning units will be installed globally in the next decade (IEA, 2017). The use of energy for space cooling has more than 
tripled between 1990 and 2016, and is growing faster than for any other end use in buildings. Most of the growth in demand is driven by economic and population growth in the hottest parts of the world, roughly equivalent to the "Global South" (i.e. developing countries). In summary, air conditioning growth will likely continue unabated, calling for a nuanced policy approach (further discussed below) and ensuring the protective benefits of mandatorily increasingly sustainable air conditioning systems particularly for vulnerable groups.

\section{What is next?}

\section{Continue expanding coverage of HHAPs}

Acknowledging the gaps in knowledge on the contribution of public health preventive efforts towards the reduction of heat-related mortality and morbidity, the existing evidence on effectiveness supports expanding the coverage of HHAPs across the European region. The broad consistency of observed HHAP protective effects and their very low economic cost compared to their large benefits (which are set to increase in a changing climate) further supports this expansion (Hunt et al., 2017). Several of the EURO member states that do not have a HHAP are routinely exposed to dangerously high temperatures, and in those countries with a national HHAP its subnational implementation can in many cases be strengthened. In particular, the current status of prevention presents a great opportunity for further involvement of local governments and community organizations in a more flexible, multi-level governance set of arrangements.

\section{Better monitoring and evaluation of HHAPs, and more research on their effectiveness}

In order to ensure the adequacy and effectiveness of existing and prospective prevention efforts, there is a clear need of strict monitoring and evaluation, not only of the purported outcomes, but also of the processes of HHAPs. Current comprehensive independent evaluations, such as the one currently underway in the UK (House of Commons, 2018b) should pave the way by continuing to bridge the gap between the actual status of implementation and population reach of the HHAPs and observed changes in heat-related mortality and morbidity. It is crucial to be able to understand the role of unmeasured factors, confounders and biases in population resilience to heat, something that most published evaluations cannot do. A stronger basis of monitoring and evaluation would facilitate sound analyses of HHAP effectiveness, which are still scarce and heterogeneous but urgently needed. More studies on heat-related mortality variation over time should be conducted based on existing methods. However, new methodologies are also needed for stricter attribution of mortality reductions over time.

Learning from local public health and governance efforts in the development and uptake of HHAPs could also be strengthened, making sure that current examples are critically assessed for their adaptability and transferability to new contexts. Choosing proxy indicators of increased heat awareness, increased socioeconomic equity or participation of vulnerable groups in design and evaluation of HHAP might be interim options while developing stronger methodologies for HHAP evaluation (Boeckmann and Zeeb, 2014).

\section{Make HHAPs dynamic}

Preventative efforts through HHAPs should mirror the dynamic nature of the relationship between temperature and health, transcending the static character of several existing plans. Interventions should be modulated to reflect different levels of warning, and take into account inter-seasonal variables like previous winter mortality. For example, population-specific temperature thresholds, which are key for calibrating HHAPs, have been observed to change over time and should be re-evaluated periodically. Studies in the US, Europe and Asia have shown statistically significant changes from one decade to the next (Gasparrini et al., 2015; Coates et al., 2014;Ng et al., 2016). Given the differences in scope and timeframe of the studies, overall conclusions are difficult to draw, but the evidence seems to suggest that at least five to six years of data would be needed to capture a significant change in temperature thresholds beyond short-term fluctuations (Miron et al., 2015). 
Moreover, periodical re-evaluation of thresholds can be used as a measuring probe of the effectiveness of adaptation measures. In general, it should be ensured that the increase temperature that the population can manage (through adaptation and acclimatization) without increased mortality would remain higher than the rate of temperature increase due to climate change. This "complete adaptation" would be modelled by holding constant the percentile definition of a heat wave (Martinez et al., 2017, 2018; Díaz et al., 2019). Under this paradigm, daily maximum temperatures qualifying as a "heat wave" (i.e. causes heat-related mortality) would in the period $2031-2080$ increase $1.4^{\circ} \mathrm{C}$ in Spain and $1.7^{\circ} \mathrm{C}$ in Finland under RCP4.5; and it would increase $2.2{ }^{\circ} \mathrm{C}$ in Iceland and $3.3^{\circ} \mathrm{C}$ in Moldova under RCP 8.5 (based on reanalysis of data by Guo et al., 2018). Anything short of these increases would mean that adaptation to heat has not been fully effective. (Díaz et al., 2019)

Thresholds can also be different for different months of the season and multiple depending on the type of health outcome and population/group of stakeholders targeted. Establishing appropriate thresholds is challenging and needs to be calibrated, as methodological research shows (Cheng et al., 2019; Xu et al., 2016)(Park and Kim, 2018). Within a given heat episode, near real-time health indicators can support better decision-making, and these have been implemented in several European countries such as the UK (Public Health England, 2018), Italy (Michelozzi et al., 2010), or France (Pascal et al., 2012), among others. Vulnerable groups may expand, contract or change over time or seasonally (e.g. outdoor workers, tourists, migrants, incarcerated populations or refugees). Larger trends and technological shifts may rapidly open avenues for preventive action that HHAP administrators should be ready and able to incorporate.

\section{Make full use of relevant available technologies}

Existing forecasting technology can already provide much improved short term and longer, seasonal forecasting of heat waves in areas, including in Europe, that do not currently benefit from them (de Perez et al., 2018). Researchers are progressively developing a better understanding of the atmospheric dynamics underlying heatwaves that will likely result in increasingly accurate predictions (Schaller et al., 2018). In addition, widespread distribution of information and communications technology, including smartphones, is enabling better forecasting and preparedness, as well as additional channels for dissemination of prevention information. A specific example is mobile apps that can be either used by individuals, such as TREASURE (Kiranoudis et al., 2016) or EXTREMA (Keramitsoglu, 2018) acquired by several municipal authorities throughout Europe to manage heat waves while providing residents with personalized heat risk assessments on their phones. Features include real-time risk maps, the location of nearby cooling centers, or a group categorization of risk for the user or relatives. Local governments are customizing the apps to their local needs, and the systems have a certain degree of modularity so that they can be coordinated with other apps such as those for pollen levels. In addition to those, it is important to highlight the progress in remote sensing (e.g. satellite driven land data assimilation systems) and data processing, as well as citizengenerated data. Big data and artificial society simulations are already being used to explore intra-urban heat vulnerability, opening possibilities for detailed but cost-effective exposure assessment (He et al., 2019). More work is needed for effective technological deployment supporting HHAPs in several areas, including standards for data and protocols, as well as more efficient means of weather data packaging for mobile devices (WHO/WMO, 2015).

\section{Critically assess the role of air conditioning and long-term urban management}

The proven health-protective effects of air conditioning should be available equitably and sustainably to vulnerable and high-risk populations, including intensive care units and nursing homes, among others. In addition, governments and institutions should continue to insist on the large and sustainable health gains that may be achieved through the implementation of passive cooling and low-carbon resilient and sustainable urban management strategies rather than on reactive solutions like air conditioning.

The scarcity of such long-term solutions within existing HHAPs underscores the need for advocacy and the urgency of action. In parallel, more precise research is needed on whether and how urban management 
interventions geared towards reducing heat impacts (such as white or green roofs, urban greening, etc) actually influence heat-related mortality and morbidity, as well as better accounting of the several health cobenefits (i.e. from physical activity, stress reduction, etc.) of such interventions. More generally, there is a clear need for reviewing the evidence and delivering recommendations on the strategic deployment of urban green infrastructure, as one in a portfolio of strategies, to reduce underlying vulnerability. However, it is important not to overstate the public health importance of such interventions versus others in the built environment, notably better insulation and improved building envelope and building codes.

Despite its undeniable benefits, the reasons to be wary of population-level over-reliance on air conditioning against heat are plenty, including its high carbon intensity, electricity use, associated production and life cycle pollution, the increase of vulnerability from air conditioning dependency, less resilience against power cuts, and possibly a challenge for physiological acclimatization (Lundgren-Kownacki et al., 2018). Its steep investment and running costs may also exacerbate inequalities. Yet, given the increasing trends of air conditioning installation, a nuanced policy approach may be advisable, based on pragmatic approaches to maximize air conditioning benefits while minimizing their greenhouse gas (GHG) emissions. These may include: 1) policies to make air conditioning units a lot more efficient, which would result in GHG emissions reductions; and 2) phasing out hydrofluorocarbons (a strategy agreed upon through the Kigali Amendment to the Montreal Protocol), which would allow for health protective benefits and relative mitigation gains in a global upwards trend of air conditioning. More research is needed on the health implications, costs and benefits of air conditioning versus alternatives such as passive cooling and improved energy performance of building envelopes. Within the WHO European region, data from EU countries show that air conditioning ownership per capita is lower than in other regions of the world (e.g. in the US and China), and most of the installed capacity is commercial rather than residential (IEA, 2017). This suggests that particular emphasis should be placed on adopting measures to keep residential air conditioning installation low by providing suitable sustainable alternatives, and possibly harnessing the potential of commercially installed air conditioning as cooling centers.

\section{Conclusion}

As more areas and populations in the WHO European region become covered by HHAPs, evaluating their implementation and effectiveness is becoming increasingly important. The evidence published in the last decade since the publication of the WHO HHAP guidance shows that the frequency, intensity and length of heat waves, as well as the exposed population, are increasing. Against this background, heat-related health impacts seem to be decreasing generally, thanks in part to preventive measures, including HHAPs. This underscores the importance of planned health adaptation, as well as its urgency across the region. The current measures and policies for the management of heat-sensitive health outcomes need modification to be effective over coming decades. Opportunities exist to develop early warning and response systems that can provide critical time to deploy proactive measures to reduce the numbers of climate-sensitive health outcomes, such as those for heat waves (Haines and Ebi, 2019).We need more research, however, about the factors that may be hindering the effectiveness of HHAPs, in particular "last mile" outreach factors and risk perceptions. Other important areas where more and more targeted research is needed include the population changes in heat sensitivity over time, best practices in HHAP governance and the preventive value of urban greening and climate-conscious urban design, among others. Notwithstanding, current evidence supports the need for expanded coverage of HHAPs, as well as better monitoring and evaluation. HHAPs can also benefit from a dynamic and proactive stance towards heat prevention, a full use of available cost-effective technologies, and a pragmatic policy approach ensuring the benefits of air conditioning for vulnerable groups while promoting long-term and low-carbon heat reduction strategies.

\section{References}

Abrahamson, V., Raine, R., 2009. Health and social care responses to the Department of Health Heatwave Plan†. J. Public Health (Bangkok). 31, 478-489. doi:10.1093/pubmed/fdp059

Abrahamson, V., Wolf, J., Lorenzoni, I., Fenn, B., Kovats, S., Wilkinson, P., Adger, W.N., Raine, R., 
2009. Perceptions of heatwave risks to health: interview-based study of older people in London and Norwich, UK. J.Public Heal. 31, 119-126.

Akompab, D., Bi, P., Williams, S., Grant, J., Walker, I., Augoustinos, M., Akompab, D.A., Bi, P., Williams, S., Grant, J., Walker, I.A., Augoustinos, M., 2013. Heat Waves and Climate Change: Applying the Health Belief Model to Identify Predictors of Risk Perception and Adaptive Behaviours in Adelaide, Australia. Int. J. Environ. Res. Public Health 10, 2164-2184. doi:10.3390/ijerph10062164

Arbuthnott, K.G., Hajat, S., 2017. The health effects of hotter summers and heat waves in the population of the $\{$ United $\{$ Kingdom\}: a review of the evidence. Env. Heal. 16, 119. doi:10.1186/s12940-017$0322-5$

Austin, S.E., Biesbroek, R., Berrang-Ford, L., Ford, J.D., Parker, S., Fleury, M.D., 2016. Public Health Adaptation to Climate Change in OECD Countries. Int. J. Environ. Res. Public Health 13. doi:10.3390/ijerph13090889

Baccini, M., Kosatsky, T., Analitis, A., Anderson, H.R., D’Ovidio, M., Menne, B., Michelozzi, P., Biggeri, A., 2011. Impact of heat on mortality in 15 European cities: attributable deaths under different weather scenarios. J. Epidemiol. Community Health 65, 64-70. doi:10.1136/jech.2008.085639

Ban, J., Wang, R., Liu, X., Li, T., Jiang, C., Shi, W., Han, L., Cui, L., 2019. Health-risk perception and its mediating effect on protective behavioral adaptation to heat waves. Environ. Res. 172, 27-33. doi:10.1016/j.envres.2019.01.006

Barreca A, Clay K, O, D., M, G., JS, S., 2016. Adapting to \{Climate\} \{Change\}: $\{$ The\} \{Remarkable\} $\{$ Decline $\}$ in the $\{$ US $\}$ Temperature $\}-\{$ Mortality $\{$ Relationship\} over the $\{$ Twentieth \{Century\}. J Polit. Econ. 124(1), 105-109.

Barriopedro, D., Fischer, E.M., Luterbacher, J., Trigo, R.M., Garcia-Herrera, R., 2011. The Hot Summer of 2010: Redrawing the Temperature Record Map of Europe. Science (80-. ). 332, 220-224. doi:10.1126/science.1201224

Bassil, K.L., Cole, D.C., 2010. Effectiveness of Public Health Interventions in Reducing Morbidity and Mortality during Heat Episodes: a Structured Review. Int. J. Environ. Res. Public Health 7, $991-$ 1001. doi:10.3390/ijerph7030991

Bittner, M.-I., Stößel, U., 2012. Perceptions of heatwave risks to health: results of an qualitative interview study with older people and their carers in Freiburg, Germany. Psychosoc. Med. 9, Doc05. doi: $10.3205 / \mathrm{psm} 000083$

Bittner, M.I., Matthies, E.F., Dalbokova, D., Menne, B., 2014. Are European countries prepared for the next big heat-wave? Eur J Public Heal. 24. doi:10.1093/eurpub/ckt121

Bobb, J.F., Peng, R.D., Bell, M.L., Dominici, F., 2014. Heat-related mortality and adaptation to heat in the United States. Environ.Health Perspect. 122, 811-816.

Boeckmann, M., Rohn, I., 2014. Is planned adaptation to heat reducing heat-related mortality and illness? A systematic review. BMC Public Health 14, 1112.

Boeckmann, M., Zeeb, H., 2014. Using a Social Justice and Health Framework to Assess European Climate Change Adaptation Strategies. Int. J. Environ. Res. Public Health 11, 12389-12411. doi:10.3390/ijerph111212389

Bohnenstengel SI, Evans S, Clark PA, Belcher SeE, 2011. Simulations of the \{London\} urban heat island. Q. J. R. Meteorol. Soc. 137(659)., 1625-1640.

Bulkeley, H., Castán Broto, V., 2013. Government by experiment? Global cities and the governing of climate change. Trans. Inst. Br. Geogr. 38, 361-375. doi:10.1111/j.1475-5661.2012.00535.x

Burkart, K., Khan, M.H., Krämer, A., Breitner, S., Schneider, A., Endlicher, W.R., 2011. Seasonal variations of all-cause and cause-specific mortality by age, gender, and socioeconomic condition in urban and rural areas of \{Bangladesh\}. Int J Equity Heal. 10, 32. doi:10.1186/1475-9276-10-32

Campbell, S., Remenyi, T.A., White, C.J., Johnston, F.H., 2018. Heatwave and health impact research: A global review. Health Place 53, 210-218. doi:10.1016/J.HEALTHPLACE.2018.08.017

Carmona, R., Diaz, J., Miron, I.J., Ortiz, C., Leon, I., Linares, C., 2016. Geographical variation in relative risks associated with cold waves in Spain: The need for a cold wave prevention plan. Environ.Int. $88,103-111$.

Carson, C., Hajat, S., Armstrong, B., Wilkinson, P., 2006. Declining vulnerability to temperature-related mortality in \{London\} over the 20th century. Am. J. Epidemiol. 164, 77-84. doi:10.1093/aje/kwj147

Castán Broto, V., Bulkeley, H., 2013. A survey of urban climate change experiments in 100 cities. Glob. 
Environ. Chang. 23, 92-102. doi:10.1016/J.GLOENVCHA.2012.07.005

Cheng, Y.-T., Lung, S.-C.C., Hwang, J.-S., 2019. New approach to identifying proper thresholds for a heat warning system using health risk increments. Environ. Res. 170, 282-292. doi:10.1016/j.envres.2018.12.059

Chung, Y., Yang, D., Gasparrini, A., Vicedo-Cabrera, A.M., Fook Sheng Ng, C., Kim, Y., Honda, Y., Hashizume, M., 2018. Changing \{Susceptibility\} to $\{$ Non\}-\{Optimum\} $\{$ Temperatures $\}$ in $\{J a p a n\}, 1972-2012:\{T h e\}\{$ Role $\}$ of $\{$ Climate $\}$, \{Demographic $\}$, and $\{$ Socioeconomic \{Factors\}. Environ. Heal. Perspect. 126, 57002. doi:10.1289/EHP2546

Ciscar, J., Feyen, L., Lavalle, C., Soria, A., Raes, F., 2014. Climate Impacts in Europe The JRC PESETA II Project. JRC Scientific and Policy Reports. Institute for Prospective and Technological Studies, Joint Research Centre, European Commission, Luxembourg.

Coates, L., Haynes, K., O’Brien, J., McAneney, J., de Oliveira, F.D., 2014. Exploring 167 years of vulnerability: $\{A n\}$ examination of extreme heat events in \{Australia\} 1844-2010. Environ. Sci. Policy 42, 33-44. doi:10.1016/j.envsci.2014.05.003

Culqui, D.R., Diaz, J., Simón, F., Tobías, A., Linares, C., 2014. Evaluation of the plan for surveillance and controlling of the effects of heat waves in \{Madrid\}. Int J Biometeorol 58, 1799-1802. doi:10.1007/s00484-013-0731-2

de’ Donato, F.K., Leone, M., Scortichini, M., De Sario, M., Katsouyanni, K., Lanki, T., Basagaña, X., Ballester, F., Åström, C., Paldy, A., Pascal, M., Gasparrini, A., Menne, B., Michelozzi, P., 2015. Changes in the $\{$ Effect $\}$ of $\{$ Heat on $\{$ Mortality in the $\{$ Last 20 \{Years $\}$ in $\{$ Nine \{European\} $\{$ Cities\}. \{Results\} from the \{PHASE\} \{Project\}. Int J Env. Res Public Heal. 12, 15567-15583. doi:10.3390/ijerph121215006

de’Donato, F., Scortichini, M., De Sario, M., de Martino, A., Michelozzi, P., 2018. Temporal variation in the effect of heat and the role of the \{Italian heat prevention plan. Public Health 161, 154-162. doi:10.1016/j.puhe.2018.03.030

de Perez, E.C., van Aalst, M., Bischiniotis, K., Mason, S., Nissan, H., Pappenberger, F., Stephens, E., Zsoter, E., van den Hurk, B., 2018. Global predictability of temperature extremes. Environ. Res. Lett. 13, 054017. doi:10.1088/1748-9326/aab94a

Díaz, J., Carmona, R., Mirón, I.J., Luna, M.Y., Linares, C., 2018. Time trend in the impact of heat waves on daily mortality in \{Spain $\}$ for a period of over thirty years (1983-2013). Env. Int 116, 10-17. doi:10.1016/j.envint.2018.04.001

Díaz, J., Sáez, M., Carmona, R., Mirón, I.J., Barceló, M.A., Luna, M.Y., Linares, C., 2019. Mortality attributable to high temperatures over the 2021-2050 and 2051-2100 time horizons in Spain: Adaptation and economic estimate. Environ. Res. 172, 475-485. doi:10.1016/j.envres.2019.02.041

Donat, M. g., Alexander, L. v., Yang, H., Durre, I., Vose, R., Caesar, J., 2013. Global \{Land $\}$-\{Based\} \{Datasets\} for \{Monitoring\} \{Climatic\} \{Extremes\}. Bull. Amer. Meteor. Soc. 94, 997-1006. doi:10.1175/BAMS-D-12-00109.1

Ebi, K.L., Teisberg, T.J., Kalkstein, L.S., Robinson, L., Weiher, R.F., Ebi, K.L., Teisberg, T.J., Kalkstein, L.S., Robinson, L., Weiher, R.F., 2004. Heat Watch/Warning Systems Save Lives: Estimated Costs and Benefits for Philadelphia 1995-98. Bull. Am. Meteorol. Soc. 85, 1067-1073. doi:10.1175/BAMS-85-8-1067

EU, 2013. Climate change adaptation: Empowerment of local and regional authorities, with a focus on their involvement in monitoring and policy design. Brussels, Belgium.

European Environment Agency, 2017. Climate change, impacts and vulnerability in \{Europe\} 2016 \{An\} indicator-based report.

Fechter-Leggett, E.D., Vaidyanathan, A., Choudhary, E., 2016. Heat \{Stress\} \{Illness\} \{Emergency\} \{Department $\{$ Visits $\}$ in $\{$ National $\}$ Environmental\} \{Public $\{$ Health $\}$ Tracking $\}$ States\}, 2005-2010. J Community Heal. 41, 57-69. doi:10.1007/s10900-015-0064-7

Forzieri, G., Cescatti, A., E Silva, F.B., Feyen, L., 2017. Increasing risk over time of weather-related hazards to the \{European\} population: a data-driven prognostic study. Lancet Planet Heal. 1, e200e208. doi:10.1016/S2542-5196(17)30082-7

Fouillet, A., Rey, G., Wagner, V., Laaidi, K., Empereur-Bissonnet, P., Le Tertre, A., Frayssinet, P., Bessemoulin, P., Laurent, F., De Crouy-Chanel, P., Jougla, E., Hémon, D., 2008. Has the impact of heat waves on mortality changed in France since the European heat wave of summer 2003? A study of the 2006 heat wave. Int. J. Epidemiol. 37, 309-17. doi:10.1093/ije/dym253

Gasparrini, A., Guo, Y., Hashizume, M., Kinney, P.L., Petkova, E.P., Lavigne, E., Zanobetti, A., 
Schwartz, J.D., Tobias, A., Leone, M., Tong, S., Honda, Y., Kim, H., Armstrong, B.G., 2015. Temporal Variation in Heat-Mortality Associations: A Multicountry Study. Environ. Health Perspect. 123, 1200-7. doi:10.1289/ehp.1409070

Gasparrini, A., Guo, Y., Sera, F., Vicedo-Cabrera, A.M., Huber, V., Tong, S., de Sousa Zanotti Stagliorio Coelho, M., Nascimento Saldiva, P.H., Lavigne, E., Matus Correa, P., Valdes Ortega, N., Kan, H., Osorio, S., Kyselý, J., Urban, A., Jaakkola, J.J.K., Ryti, N.R.I., Pascal, M., Goodman, P.G., Zeka, A., Michelozzi, P., Scortichini, M., Hashizume, M., Honda, Y., Hurtado-Diaz, M., Cesar Cruz, J., Seposo, X., Kim, H., Tobias, A., Iñiguez, C., Forsberg, B., Åström, D.O., Ragettli, M.S., Guo, Y.L., Wu, C., Zanobetti, A., Schwartz, J., Bell, M.L., Dang, T.N., Van, D. Do, Heaviside, C., Vardoulakis, S., Hajat, S., Haines, A., Armstrong, B., 2017. Projections of temperature-related excess mortality under climate change scenarios. Lancet Planet. Heal. 1, e360-e367. doi:https://doi.org/10.1016/S2542-5196(17)30156-0

GHHIN, 2018. Heat health action plans database. Global Heat Health Information Network. [WWW Document].

Gil Cuesta, J., van Loenhout, J.A., Colaco, M.D., Guha-Sapir, D., 2017. General Population Knowledge about Extreme Heat: A Cross-Sectional Survey in Lisbon and Madrid. Int. J. Environ. Res. Public Health 14, 10.3390/ijerph14020122. doi:E122 [pii]

Green, H.K., Andrews, N., Armstrong, B., Bickler, G., Pebody, R., 2016. Mortality during the 2013 heatwave in $\{$ England $\}-$ - How $\}$ did it compare to previous heatwaves? $\{A\}$ retrospective observational study. Environ. Res. 147, 343-349. doi:10.1016/j.envres.2016.02.028

Guo, Y., Gasparrini, A., Li, S., Sera, F., Vicedo-Cabrera, A.M., de Sousa Zanotti Stagliorio Coelho, M., Saldiva, P.H.N., Lavigne, E., Tawatsupa, B., Punnasiri, K., Overcenco, A., Correa, P.M., Ortega, N.V., Kan, H., Osorio, S., Jaakkola, J.J.K., Ryti, N.R.I., Goodman, P.G., Zeka, A., Michelozzi, P., Scortichini, M., Hashizume, M., Honda, Y., Seposo, X., Kim, H., Tobias, A., Íñiguez, C., Forsberg, B., Åström, D.O., Guo, Y.L., Chen, B.-Y., Zanobetti, A., Schwartz, J., Dang, T.N., Van, D. Do, Bell, M.L., Armstrong, B., Ebi, K.L., Tong, S., 2018. Quantifying excess deaths related to heatwaves under climate change scenarios: $\{A\}$ multicountry time series modelling study. PLoS Med. 15, e1002629. doi:10.1371/journal.pmed.1002629

Ha, J., Kim, H., 2013. Changes in the association between summer temperature and mortality in Seoul, South Korea. Int.J.Biometeorol. 57, 535-544.

Haines, A., Ebi, K., 2019. The Imperative for Climate Action to Protect Health. N. Engl. J. Med. 380, 263-273. doi:10.1056/NEJMra1807873

Hajat, S., Vardoulakis, S., Heaviside, C., Eggen, B., 2014. Climate change effects on human health: projections of temperature-related mortality for the United Kingdom during the 2020s, 2050s and 2080s. J Epidemiol Community Heal 68. doi:10.1136/jech-2013-202449

Hatvani-Kovacs, G., Belusko, M., Pockett, J., Boland, J., 2018. Heat stress-resistant building design in the Australian context. Energy Build. 158, 290-299. doi:10.1016/J.ENBUILD.2017.10.025

He, C., Ma, L., Zhou, L., Kan, H., Zhang, Y., Ma, W., Chen, B., 2019. Exploring the mechanisms of heat wave vulnerability at the urban scale based on the application of big data and artificial societies. Environ. Int. 127, 573-583. doi:10.1016/J.ENVINT.2019.01.057

Heaviside, C., Macintyre, H., Vardoulakis, S., 2017. The Urban Heat Island: Implications for Health in a Changing Environment. Curr Env. Heal. Rep 4, 296-305. doi:10.1007/s40572-017-0150-3

Herrmann, A., Sauerborn, R., 2018. General Practitioners' Perceptions of Heat Health Impacts on the Elderly in the Face of Climate Change-A Qualitative Study in Baden-Württemberg, Germany. Int. J. Environ. Res. Public Health 15. doi:10.3390/ijerph15050843

Hondula, D.M., Davis, R.E., Georgescu, M., 2018. Clarifying the Connections Between Green Space, Urban Climate, and Heat-Related Mortality. Am. J. Public Health 108, S62-S63. doi:10.2105/AJPH.2017.304295

House of Commons, 2018a. Heatwaves: adapting to climate change. London, UK.

House of Commons, 2018b. Heatwaves: adapting to climate change - Government Response to the Committee's Ninth Report. London, UK.

Howarth, C., Kantenbacher, J., Guida, K., Roberts, T., Rohse, M., 2019. Improving resilience to hot weather in the UK: The role of communication, behaviour and social insights in policy interventions. Environ. Sci. Policy 94, 258-261. doi:10.1016/J.ENVSCI.2019.01.008

Howe, P.D., Marlon, J.R., Wang, X., Leiserowitz, A., 2019. Public perceptions of the health risks of extreme heat across US states, counties, and neighborhoods. Proc. Natl. Acad. Sci. U. S. A. 116, 
6743-6748. doi:10.1073/pnas.1813145116

Hunt, A., Ferguson, J., Baccini, M., Watkiss, P., Kendrovski, V., 2017. Climate and weather service provision: Economic appraisal of adaptation to health impacts. Clim. Serv. 7, 78-86. doi:10.1016/J.CLISER.2016.10.004

IEA, 2017. The Future of Cooling: Opportunities for energy efficient air conditioning. International Energy Agency, Vienna, Austria.

IPCC, 2013. Climate Change 2013: The Physical Science Basis. Contribution of Working Group I to the Fifth Assessment Report of the Intergovernmental Panel on Climate Change. Cambridge University Press, Cambridge, United Kingdom and New York, NY, USA.

Jacob, D, Petersen, J., Eggert, B, Alias, A, Christensen,O, et al, 2014. \{EURO $\}$ - $\{$ CORDEX $\}:\{N e w\}$ high-resolution climate change projections for \{European\} impact research. Reg. Environ. Chang. 14, 563-578. doi:10.1007/s10113-013-0499-2).

Jepson, R.G., Harris, F.M., Platt, S., Tannahill, C., Marmot, M., Mezoff, J., Miller, K., Pappas-Deluca, K., Woolf, S., Sutton, S., Lux, L., Whitener, L., 2010. The effectiveness of interventions to change six health behaviours: a review of reviews. BMC Public Health 10, 538. doi:10.1186/1471-2458-10-538

Keramitsoglu, I., 2018. Emergency notification systems for extreme temperatures [WWW Document]. Extrem. Proj. website. URL https://extrema.space/ (accessed 11.19.18).

Kiranoudis, C., Keramitsoglu, I., Giannakopoulos, C., Founda, D., Katsouyanni, K., Analitis, A., Ordonez, D., Butler, T., Sismanidis, P., 2016. TREASURE App website [WWW Document]. TREASURE Proj. Site. URL http://snf-652558.vm.okeanos.grnet.gr/treasure/portal/info.html (accessed 12.8.18).

Klenk, J., Becker, C., Rapp, K., 2010. Heat-related mortality in residents of nursing homes. Age Ageing 39, 245-252. doi:10.1093/ageing/afp248

Kyselý, J., Kríz, B., 2008. Decreased impacts of the 2003 heat waves on mortality in the \{Czech\} \{Republic\}: an improved response? Int J Biometeorol 52, 733-745. doi:10.1007/s00484-008-0166-3

Lehner, F., Deser, C., Sanderson, B.M., 2018. Future risk of record-breaking summer temperatures and its mitigation. Clim. Change 146, 363-375. doi:10.1007/s10584-016-1616-2

Levi, M., Kjellstrom, T., Baldasseroni, A., 2018. Impact of climate change on occupational health and productivity: a systematic literature review focusing on workplace heat. Med. Lav. 109, 163-179. doi:10.23749/MDL.V109I3.6851

Li, J., Xu, X., Ding, G., Zhao, Y., Zhao, R., Xue, F., Li, J., Gao, J., Yang, J., Jiang, B., Liu, Q., 2016. A Cross-Sectional Study of Heat Wave-Related Knowledge, Attitude, and Practice among the Public in the Licheng District of Jinan City, China. Int. J. Environ. Res. Public Health 13, 10.3390/ijerph13070648. doi:10.3390/ijerph13070648 [doi]

Linares, C., Sánchez, R., Mirón, I.J., Díaz, J., 2015. Has there been a decrease in mortality due to heat waves in \{Spain\}? \{Findings\} from a multicity case study. J. Integr. Environ. Sci. 12, 153-163. doi:10.1080/1943815X.2015.1062032

López-Bueno, J.A., Díaz, J., Linares, C., 2019. Differences in the impact of heat waves according to urban and peri-urban factors in Madrid. Int. J. Biometeorol. 63, 371-380. doi:10.1007/s00484-019-016709

Lorencatto, F., West, R., Seymour, N., Michie, S., 2013. Developing a method for specifying the components of behavior change interventions in practice: The example of smoking cessation. J. Consult. Clin. Psychol. 81, 528-544. doi:10.1037/a0032106

Loughnan, M., Carroll, M., Tapper, N.J., 2015. The relationship between housing and heat wave resilience in older people. Int. J. Biometeorol. 59, 1291-1298. doi:10.1007/s00484-014-0939-9

Lowe, D., Ebi, K.L., Forsberg, B., 2011. Heatwave early warning systems and adaptation advice to reduce human health consequences of heatwaves. Int. J. Environ. Res. Public Health 8, 4623-4648. doi:10.3390/ijerph8124623

Lundgren-Kownacki, K., Hornyanszky, E.D., Chu, T.A., Olsson, J.A., Becker, P., 2018. Challenges of using air conditioning in an increasingly hot climate. Int. J. Biometeorol. 62, 401-412. doi:10.1007/s00484-017-1493-z

MacIntyre, E., Khanna, S., Darychuk, A., Copes, R., Schwartz, B., 2019. Evidence synthesis - Evaluating risk communication during extreme weather and climate change: a scoping review. Heal. Promot. Chronic Dis. Prev. Canada 39, 142-156. doi:10.24095/hpcdp.39.4.06

Madrigano, J., Lane, K., Petrovic, N., Ahmed, M., Blum, M., Matte, T., 2018. Awareness, Risk Perception, and Protective Behaviors for Extreme Heat and Climate Change in New York City. Int. J. Environ. 
Res. Public Health 15, 1433. doi:10.3390/ijerph15071433

Martinez, G., Imai, C., Masumo, K., 2011. Local heat stroke prevention plans in Japan: characteristics and elements for public health adaptation to climate change. Int. J. Environ. Res. Public Health 8, 4563 81. doi:10.3390/ijerph8124563

Martinez, G.S., Diaz, J., Hooyberghs, H., Lauwaet, D., De Ridder, K., Linares, C., Carmona, R., Ortiz, C., Kendrovski, V., Adamonyte, D., 2018. Cold-related mortality vs heat-related mortality in a changing climate: A case study in Vilnius (Lithuania). Environ. Res. 166, 384-393. doi:10.1016/J.ENVRES.2018.06.001

Martinez, G.S., Hooyberghs, H., Bekker-Nielsen Dunbar, M., Linares, C., Kendrovski, V., Aerts, R., Van Nieuwenhuyse, A., Carmona, R., Diaz, J., De Ridder, K., Lauwaet, D., Ortiz, C., 2017. Heat and health in Antwerp under climate change: Projected impacts and implications for prevention. Environ. Int. 111, 135-143. doi:10.1016/j.envint.2017.11.012

Matthies, F., Menne, B., 2009. Prevention and management of health hazards related to heatwaves. Int. J. Circumpolar Health 68, 8-12. doi:10.3402/ijch.v68i1.18293

Matzarakis, A., 2017. The Heat Health Warning System of DWD—Concept and Lessons Learned. Springer, Cham, pp. 191-196. doi:10.1007/978-3-319-35095-0_27

Mayrhuber, E.A.-S., Dückers, M.L.A., Wallner, P., Arnberger, A., Allex, B., Wiesböck, L., Wanka, A., Kolland, F., Eder, R., Hutter, H.-P., Kutalek, R., 2018. Vulnerability to heatwaves and implications for public health interventions - $\{\mathrm{A}\}$ scoping review. Environ. Res. 166, 42-54. doi:10.1016/j.envres.2018.05.021

Memon, R.A., Leung, D.Y.C., Chunho, L., 2008. A review on the generation, determination and mitigation of urban heat island. J Env. Sci 20, 120-128.

Michelozzi, P., de' Donato, F.K., Bargagli, A.M., D’Ippoliti, D., De Sario, M., Marino, C., Schifano, P., Cappai, G., Leone, M., Kirchmayer, U., Ventura, M., di Gennaro, M., Leonardi, M., Oleari, F., De Martino, A., Perucci, C.A., 2010. Surveillance of summer mortality and preparedness to reduce the health impact of heat waves in \{Italy\}. Int J Env. Res Public Heal. 7, 2256-2273. doi:10.3390/ijerph7052256

Michie, S., Hyder, N., Walia, A., West, R., 2011. Development of a taxonomy of behaviour change techniques used in individual behavioural support for smoking cessation. Addict. Behav. 36, 315319. doi:10.1016/j.addbeh.2010.11.016

Michie, S., Richardson, M., Johnston, M., Abraham, C., Francis, J., Hardeman, W., Eccles, M.P., Cane, J., Wood, C.E., 2013. The Behavior Change Technique Taxonomy (v1) of 93 Hierarchically Clustered Techniques: Building an International Consensus for the Reporting of Behavior Change Interventions. Ann. Behav. Med. 46, 81-95. doi:10.1007/s12160-013-9486-6

Miron, I.J., Linares, C., Montero, J.C., Criado-Alvarez, J.J., Diaz, J., 2015. Changes in cause-specific mortality during heat waves in central Spain, 1975-2008. Int.J.Biometeorol. 59, 1213-1222.

Montero, J.C., Miron, I.J., Criado-Alvarez, J.J., Linares, C., Diaz, J., 2012. Influence of local factors in the relationship between mortality and heat waves: Castile-La Mancha (1975-2003). Sci. Total Environ. 414, 73-80. doi:10.1016/j.scitotenv.2011.10.009

Muthers, S., Matzarakis, A., Koch, E., Muthers, S., Matzarakis, A., Koch, E., 2010. Climate $\{$ Change $\}$ and $\{$ Mortality $\}$ in $\{$ Vienna $\}-\{A\}\{$ Human $\}$ BBiometeorological $\}$ Analysis $\}$ Based $\}$ on $\{$ Regional $\}$ \{Climate\} \{Modeling\}. Int. J. Environ. Res. Public Health 7, 2965-2977. doi:10.3390/ijerph7072965

Ng, C.F.S., Boeckmann, M., Ueda, K., Zeeb, H., Nitta, H., Watanabe, C., Honda, Y., 2016. Heat-related mortality: \{Effect\} modification and adaptation in \{Japan\} from 1972 to 2010. Glob. Environ. Chang. 39, 234-243. doi:10.1016/j.gloenvcha.2016.05.006

Nitschke, M., Tucker, G.R., Hansen, A.L., Williams, S., Zhang, Y., Bi, P., 2011. Impact of two recent extreme heat episodes on morbidity and mortality in \{Adelaide\}, \{South\} \{Australia\}: a case-series analysis. Env. Heal. 10, 42. doi:10.1186/1476-069X-10-42

O’Neill, B.C., Kriegler, E., Ebi, K.L., Kemp-Benedict, E., Riahi, K., Rothman, D.S., van Ruijven, B.J., van Vuuren, D.P., Birkmann, J., Kok, K., Levy, M., Solecki, W., 2017. The roads ahead: Narratives for shared socioeconomic pathways describing world futures in the 21st century. Glob. Environ. Chang. 42, 169-180. doi:10.1016/j.gloenvcha.2015.01.004

Park, J., Kim, J., 2018. Defining heatwave thresholds using an inductive machine learning approach. PLoS One 13, e0206872. doi:10.1371/journal.pone.0206872

Pascal, M., Laaidi, K., Wagner, V., Ung, A.B., Smaili, S., Fouillet, A., Caserio-Schönemann, C., Beaudeau, 
P., 2012. How to use near real-time health indicators to support decision-making during a heat wave: the example of the French heat wave warning system. PLoS Curr. 4, e4f83ebf72317d. doi:10.1371/4f83ebf72317d

Pascal, M., Sweeney, J., Cullen, E., Schwartz, J., Goodman, P., 2013. Heatwave and mortality in \{Ireland\}, planning for the future. Irish Geogr. 46,

Pascal, M., Wagner, V., Corso, M., Laaidi, K., Le Tertre, A., 2019. Évolution de l'exposition aux canicules et de la mortalité associée en France métropolitaine entre 1970 et 2013. Santé publique Fr.

Petkova, E.P., Gasparrini, A., Kinney, P.L., 2014. Heat and mortality in $\{\mathrm{New}\}$ YYork\}\{City\} since the beginning of the 20th century. Epidemiology 25, 554-560. doi:10.1097/EDE.0000000000000123

Public Health England, 2018. Heatwave plan for England, Heatwave plan for England \& Wales. Public Health England, London.

Ragettli, M.S., Röösli, M., 2019. Hitzeaktionspläne zur Prävention von hitzebedingten Todesfällen Erfahrungen aus der Schweiz. Bundesgesundheitsblatt - Gesundheitsforsch. - Gesundheitsschutz 62, 605-611. doi:10.1007/s00103-019-02928-8

Robine, J.-M., Cheung, S.L.K., Le Roy, S., Van Oyen, H., Griffiths, C., Michel, J.-P., Herrmann, F.R., 2008. Death toll exceeded 70,000 in Europe during the summer of 2003. C. R. Biol. 331, 171-178. doi:10.1016/j.crvi.2007.12.001

Roldan, E., Gomez, M., Pino, M.R., Diaz, J., 2014. The impact of extremely high temperatures on mortality and mortality cost. Int. J. Environ. Health Res. 1-11. doi:10.1080/09603123.2014.938028

Russo, S., Sillmann, J., Fischer, E.M., 2015. Top ten \{European\} heatwaves since 1950 and their occurrence in the coming decades. Environ. Res. Lett. 10, 124003. doi:10.1088/1748$9326 / 10 / 12 / 124003$

Schaller, N., Sillmann, J., Anstey, J., Fischer, E.M., Grams, C.M., Russo, S., 2018. Influence of blocking on Northern European and Western Russian heatwaves in large climate model ensembles. Environ. Res. Lett. 13, 054015. doi:10.1088/1748-9326/aaba55

Schifano, P., Leone, M., De Sario, M., de’Donato, F., Bargagli, A.M., D’Ippoliti, D., Marino, C., Michelozzi, P., 2012. Changes in the effects of heat on mortality among the elderly from 1998-2010: results from a multicenter time series study in Italy. Environ. Health 11, 58. doi:10.1186/1476069X-11-58

Scortichini, M., de’Donato, F., De Sario, M., Leone, M., Åström, C., Ballester, F., Basagaña, X., Bobvos, J., Gasparrini, A., Katsouyanni, K., Lanki, T., Menne, B., Pascal, M., Michelozzi, P., 2018. The interannual variability of heat-related mortality in nine \{European\} cities (1990-2010). Env. Heal. 17, 66. doi:10.1186/s12940-018-0411-0

Sheridan, S.C., Allen, M.J., 2018. Temporal trends in human vulnerability to excessive heat. Environ. Res. Lett. 13, 43001. doi:10.1088/1748-9326/aab214

Sherwood, S.C., Huber, M., 2010. An adaptability limit to climate change due to heat stress. Proc. Natl. Acad. Sci. 107, 9552-9555. doi:10.1073/pnas.0913352107

Smoyer, K.E., Rainham, D.G., Hewko, J.N., 2000. Heat-stress-related mortality in five cities in Southern Ontario: 1980-1996. Int J Biometeorol 44, 190-197.

Takahashi, N., Nakao, R., Ueda, K., Ono, M., Kondo, M., Honda, Y., Hashizume, M., 2015. Community trial on heat related-illness prevention behaviors and knowledge for the elderly. Int. J. Environ. Res. Public Health 12, 3188-214. doi:10.3390/ijerph120303188

Tan, J., Zheng, Y., Tang, X., Guo, C., Li, L., Song, G., Zhen, X., Yuan, D., Kalkstein, A.J., Li, F., 2010. The urban heat island and its impact on heat waves and human health in \{Shanghai\}. Int $\mathrm{J}$ Biometeorol 54, 75-84. doi:10.1007/s00484-009-0256-x

Toloo, G., FitzGerald, G., Aitken, P., Verrall, K., Tong, S., 2013. Evaluating the effectiveness of heat warning systems: systematic review of epidemiological evidence. Int. J. Public Health 58, 667-81. doi:10.1007/s00038-013-0465-2

UKDH, 2011. Local government leading for public health. London, UK.

Ung, A., Corso, M., Pascal, M., Laaidi, K., Wagner, V., Beaudeau, P., 2019. Évaluation de la surmortalité pendant les canicules des étés 2006 et 2015 en France métropolitaine. Santé publique Fr.

van Loenhout, J., Rodriguez-Llanes, J., Guha-Sapir, D., 2016. Stakeholders' Perception on National Heatwave Plans and Their Local Implementation in Belgium and The Netherlands. Int. J. Environ. Res. Public Health 13, 1120. doi:10.3390/ijerph13111120

van Loenhout, J.A.F., Guha-Sapir, D., 2016. How resilient is the general population to heatwaves? A knowledge survey from the ENHANCE project in Brussels and Amsterdam. BMC Res. Notes 9, 
499. doi:10.1186/s13104-016-2305-y

WHO/WMO, 2015. Heatwaves and Health: Guidance on Warning-System Development. World Health Organization, Geneva, Switzerland.

WHO, 2011. Public health advice on preventing health effects of heat. New and updated information for different audiences. World Health Organization Regional Office for Europe, Copenhagen, Denmark.

WHO, 2008. WHO guide for standardization of economic evaluations of immunization programmes. World Health Organization, Geneva, Switzerland.

Wilby, R.L., Jones, P.D., Lister, D.H., 2011. Decadal variations in the nocturnal heat island of London. Weather 66, 59-64.

Wolf, J., Adger, W.N., Lorenzoni, I., 2010a. Heat $\{$ Waves $\}$ and $\{$ Cold $\}$ Spells\}: $\{$ An $\}$ Analysis $\}$ of \{Policy $\{$ Response $\}$ and $\{$ Perceptions $\}$ of $\{$ Vulnerable $\}$ Populations $\}$ in the $\{\mathrm{UK}\}$. Env. Plan A 42, 2721-2734. doi:10.1068/a42503

Wolf, J., Adger, W.N., Lorenzoni, I., Abrahamson, V., Raine, R., 2010b. Social capital, individual responses to heat waves and climate change adaptation: An empirical study of two UK cities. Glob. Environ. Chang. 20, 44-52. doi:10.1016/J.GLOENVCHA.2009.09.004

Wu, J., Zhou, Y., Gao, Y., Fu, J.S., Johnson, B.A., Huang, C., Kim, Y.-M., Liu, Y., 2014. Estimation and Uncertainty Analysis of Impacts of Future Heat Waves on Mortality in the Eastern United States. Environ. Health Perspect. 122, 10-16. doi:10.1289/ehp.1306670

Xu, X., Li, J., Gao, J., Liu, K., Liu, Q., 2018. Effective analysis of a community-based intervention during heat waves to improve knowledge, attitude and practice in a population in Licheng District, Jinan City, China. J. Public Health (Bangkok). 40, 573-581. doi:10.1093/pubmed/fdx121

Xu, Z., FitzGerald, G., Guo, Y., Jalaludin, B., Tong, S., 2016. Impact of heatwave on mortality under different heatwave definitions: A systematic review and meta-analysis. Environ. Int. 89-90, 193203. doi:10.1016/J.ENVINT.2016.02.007

Ye, H., Ma, J., Wu, Y., Zhang, Y., 2018. Perceptions of Health Risks from Hot Weather, and Coping Behaviors among Ethnic Minority Groups in Mountain Areas of China: A Case Study in the Tujia and Miao Autonomous Prefecture. Int. J. Environ. Res. Public Health 15, 2498.

doi:10.3390/ijerph15112498 